\title{
O benefício microclimático proporcionado pela Praça Alfredo Ander- sen na cidade de Curitiba-PR
}

\author{
Microclimate benefits provided by Alfredo Andersen Square in Curitiba-PR \\ Jennifer Viezzer ${ }^{1}$, Daniela Biondi ${ }^{2}$, Angeline Martini ${ }^{3}$ e Dâmaris Araújo da Silva ${ }^{4}$ \\ 1, 2,3,4 Departamento de Ciências Florestais, UFPR
}

\begin{abstract}
Resumo
O objetivodeste trabalho foi analisar a influência microclimática da Praça Alfredo Andersen na cidadedeCuritiba - PR. Esta praça é arborizada e possui 24 indivíduos arbóreos de grande porte. Sua influência microclimática foi analisada por meio de um levantamento meteorológico expedito. Para isso, foram utilizadasduas miniestações da

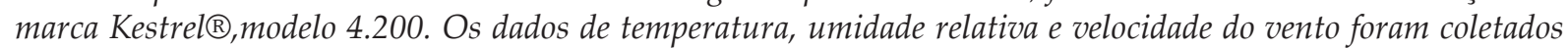
simultaneamente no centro da praça e em um transecto móvel percorrido pela Al.Augusto Stellfeld. Percorreu-se a pé aproximadamente $1.000 \mathrm{~m}$ ao longo da via, sendo que os dados meteorológicos foram coletados a cada $50 \mathrm{~m}$. Os resultados indicam que, em média, a temperatura na praça foi $1,4{ }^{\circ}$ menor do que no transecto e a velocidade do vento foi $0,29 \mathrm{~m} / \mathrm{s}$ menor. A umidade relativa na praça foi $5 \%$ maior. A existência de arborização na Al. Augusto Stellfeld dificultou a interpretação dos resultados, pois alguns pontos foram coletados embaixo de árvores. Pelo mesmo motivo, o raio de influência desta praça no seu entorno não pode ser determinado, sendo observado a apenas 200 m. Conclui-se que a Praça Alfredo Andersen contribui para a melhoria microclimática da cidade de Curitiba.
\end{abstract}

Palavras-chave: Áreas Verdes. Espaços abertos. Microclima Urbano. Temperatura. Umidade relativa.

\begin{abstract}
The aim of this study was to investigate the microclimate influence of Alfredo Andersen Square in the city of Curitiba - PR. This square is a wooded area, with 24 large-sized trees. Its microclimate influence was analyzed with a promptly meteorological data collection, using two Kestrel@'s mini-stations, model 4,200.The data on temperature, humidity and wind speed, werecollected simultaneously in the center of thesquare and in a mobile transect on Augusto Stellfeld Ave. The transect had approximately 1,000 m, with the meteorological data collected every $50 \mathrm{~m}$. The results showed that, on average, the temperature in the square was $1.4^{\circ} \mathrm{C}$ lower than on the avenue, the wind speed was $0.29 \mathrm{~m} / \mathrm{s}$ lower, and the humidity was $5 \%$ higher. Since there are urban trees along Augusto Stellfeld Ave., some data from the mobile transect were collected under those trees, which interfered on the results interpretation. Hence, the influence radius of this square on its surroundings could not be determined, being observed only for $200 \mathrm{~m}$. We concluded that Alfredo Andersen Sq collaborates to improve the urban microclimate in the city of Curitiba.
\end{abstract}

Keywords: Green Areas. Open Spaces. Urban microclimate. Temperature. Relative humidity. 


\section{Introdução}

A maior parte da população mundial vive hoje em centros urbanos, regiões profundamente alteradas pela ação antrópica e vulneráveis física e socialmente (MATOS et al., 2010). As condições de artificialidade das cidades e a urbanização têm gerado prejuízos para o bem-estar e para a qualidade de vida da população, e ocasionado grandes impactos no clima.

Nas áreas densamente urbanizadas, os edifícios, os veículos, os processos industriais, e até mesmo as pessoas são responsáveis por produzir calor elevado e por influenciar significativamente na formação de "Ilhas de Calor Urbano" (GARTLAND, 2010). Desta forma, acidade é geradora de um clima próprio, resultante da interferência de todos os fatores que se processam sobre a camada de limite urbano e que agem no sentido de alterar o clima em escala local (AMORIM, 2010).

Neste contexto, a inserção da vegetação nas áreas urbanas é uma das principais estratégias para reduzir o efeito das ilhas de calor, uma vez que as plantas apresentam importante papel na regulação do clima urbano $(Y u, 2006)$. A presença da vegetação em áreas urbanas pode gerar um resfriamento localizado que se contrapõe ao efeito das ilhas de calor, fenômeno conhecido como "Ilhas de Frescor Urbano" (SHASHUA-BAR; PEARLMUTTER; ERELL, 2009).

Sabe-se que parte dos impactos ocasionados pela urbanização pode ser amenizada pelo planejamento urbano, ampliando-se qualitativa e quantitativamente a arborização urbana (MILANO, 1987). Segundo Lombardo et al. (2012), as áreas verdes urbanas são componentes estratégicos da cidade, pois contribuem com o ciclo hidrológico, controle de erosões, estabilização de encostas, e regulação dos fluxos em canais de drenagem; oferecem áreas de sombreamento, retenção de partículas, e redução do ruído; além de contribuírem para a democratização de espaços para práticas de lazer, atividades de educação ambiental e amenização térmica.Estes efeitos não se restringem apenas ao local onde a área verde se encontra, mas contribui também para estabilizar o microclima dos arredores imediatos (SUCOMINE et al., 2009).

Entre as diferentes tipologias de áreas verdes urbanas, a praça é a mais presente e identificada, no Brasil e no mundo (BIONDI; LIMA NETO, 2012). As praças brasileiras são espaços planejados e ajardinados (ROBBA; MACEDO, 2010) que representam um espaço público de grande importância no cotidiano urbano, e pode ser definida de maneira ampla como qualquer espaço público urbano, livre de edificações, que propicie convivência e/ ou recreação para os seus usuários (VIERO; BARBOSA FILHO, 2009).

Por geralmente serem pequenas, as praças possuem uma maior distribuição pela cidade, permitindo também que um maior número de habitantes esteja próximo a uma área verde (BRITO et al., 2012).
Hamada e Otha (2010) afirmam que há poucos dados sobre a relação entre o tamanho da área verde e o efeito de resfriamento, tornando-se necessário entender como estas áreas ajudam a diminuir as temperaturas nas áreas urbanas próximas. Além disso, Leal et al. (2011) ressaltam que, para entender melhor a importância dos benefícios microclimáticos das áreas verdes da cidade, deve-se comparar o seu microclima interno com a sua área externa.

Devido à necessidade de maiores estudos neste tema para subsidiar o planejamento de áreas verdes, o objetivo da presente pesquisa foi analisar a influência microclimática da Praça Alfredo Andersen na cidade de Curitiba-PR.

\section{Material e Métodos}

A pesquisa foi realizada na Praça Alfredo Andersen, situada nas coordenadas geográficas $25^{\circ} 26^{\prime} 3.61^{\prime \prime} \mathrm{S}$ e $49^{\circ}$ 17' 28.25" W, no bairro Bigorrilho, em Curitiba, capital do estado do Paraná. Esta área verde é circundada pela Alameda Augusto Stellfelde pela RuaCapitão Souza Franco, e foi implantada no ano de 1969.

A praça apresenta $4.365 \mathrm{~m}^{2}$ de área total, e uma área permeável de $57,43 \%$.No levantamento realizado para esta pesquisa, foram encontrados 24 indivíduos arbóreos de grande porte, representados pelas seguintes espécies:Anadenanthera colubrina (Vell.) Brenan, Peltophorum dubium (Spreng.) Taub., Chorisia speciosa A. St.-Hil., Jacaranda mimosaefolia D. Don, e Cedrela fissilis Vell. Os nomes populares destas espécies são: monjoleiro, canafístula, paineira, jacarandá-mimoso e cedro-rosa, respectivamente.

A praça está inserida no Zoneamento Residencial 4 (ZR4), que compreendezonas residenciais de média-alta densidade, onde se permitem habitações coletivas, habitação transitória ou habitação institucional até seis pavimentos, além de comércio e serviço vicinal ou de bairro com porte de $200 \mathrm{~m}^{2}$ e ocupação de $50 \%$.

A influência desta área verde no microclima da cidade foi realizada a partir de um levantamento meteorológico expedito, conforme metodologia adaptada de Leal et al. (2011). Para isto, foram utilizadas duas mini-estações da marca Kestrel ${ }^{\circledR}$, modelo 4.200, mantidas a uma altura de 1,50m. Uma mini-estação permaneceu sob cuidados de um pesquisador no centro da praça, para servir de testemunha e a outra foi utilizada no transecto móvel, percorrido a pé por outro pesquisador. Este percurso se iniciou na bordadura da praça e se estendeu pela Al. Augusto Stellfeld até alcançar a distância de aproximadamente $1.000 \mathrm{~m}$.

O trajeto do transecto móvel foi definido considerando-se um caminho que poderia ser percorrido em curto espaço de tempo, minimizando os efeitos das diferentes intensidades de radiação produzidas pela variação da altura aparente do sol no mesmo período, evitando a 


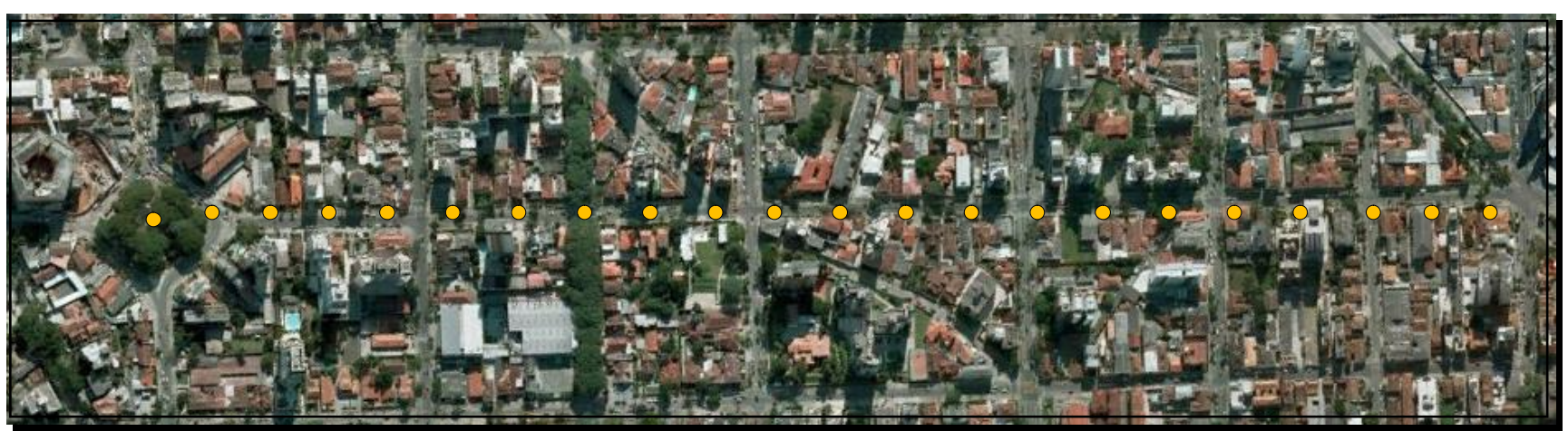

Figura 1 - Localização nos pontos de coleta de dados meteorológicos, no interior da praça e no transecto móvel

necessidade de correção dos dados de acordo com o período de medição (LEAL et al. 2011).

Os dados meteorológicos foram coletados simultaneamente entre o equipamento localizado na praça e o equipamento utilizado no transecto móvel, uma vez que foram programados para coleta de informações a cada minuto. No percurso padronizou-se o mesmo ritmo de caminhada, sendo que a distância entre os pontos coletados foi de 50m (Figura 1).

A coleta de dados foi realizada no dia 16 de abril de 2013, dia de céu com poucas nuvens. O horário do estudo foi entre $12 \mathrm{~h}$ e $12 \mathrm{~h} 20$, totalizando 21 leituras. As variáveis meteorológicas utilizadas foram: temperatura do ar $\left({ }^{\circ} \mathrm{C}\right)$, umidade relativa do ar (\%) e velocidade do vento $(\mathrm{m} / \mathrm{s})$.
As médias dos dados meteorológicos obtidos na praça e no percurso realizado foram comparadas estatisticamente pelo teste $\mathrm{t}$ a $99 \%$ de significância. Além disso, realizou-se uma análise das diferenças.

\section{Resultados e Discussão}

Os resultados mostraram diferenças estatísticas significativas entre o microclima no interior da área verde e no transecto móvel percorrido para todas as variáveis analisadas (Tabela 1). Ao longo do transecto percorrido, a temperatura foi em média $1,4{ }^{\circ} \mathrm{C}$ mais elevada do que no interior da área verde e a velocidade do vento $0,29 \mathrm{~m} / \mathrm{s}$. A umidade relativa no interior da área verde

Tabela 1 - Dados meteorológicos obtidos no interior da área verde (IAV) e no transecto móvel (TM), suasdiferenças e análise estatística

\begin{tabular}{|c|c|c|c|c|c|c|c|c|c|}
\hline \multirow{2}{*}{$\begin{array}{c}\text { Distância } \\
(\mathrm{m})\end{array}$} & \multicolumn{3}{|c|}{ Temperatura $\left({ }^{\circ} \mathrm{C}\right)$} & \multicolumn{3}{c|}{ Umidade Relativa $(\%)$} & \multicolumn{3}{c|}{ Velocidade do vento (m/s) } \\
\cline { 2 - 10 } & IAV & TM & Diferença & IAV & TM & Diferença & IAV & TM & Diferença \\
\hline 0 & 19,9 & 20,8 & 0,9 & 55,2 & 50,0 & 5,2 & 0,0 & 0,7 & 0,7 \\
\hline 50 & 20,1 & 21,1 & 1,0 & 54,9 & 50,0 & 4,9 & 0,0 & 0,4 & 0,4 \\
\hline 100 & 20,2 & 21,3 & 1,1 & 55,3 & 50,1 & 5,2 & 0,0 & 0,3 & 0,3 \\
\hline 150 & 20,7 & 22,7 & 2,0 & 54,7 & 49,1 & 5,6 & 0,0 & 0,9 & 0,9 \\
\hline 200 & 20,7 & 21,5 & 0,8 & 54,1 & 48,6 & 5,5 & 0,0 & 1,1 & 1,1 \\
\hline 250 & 20,8 & 20,8 & 0,0 & 54,4 & 50,9 & 3,5 & 0,0 & 0,4 & 0,4 \\
\hline 300 & 20,1 & 21,6 & 1,5 & 54,4 & 51,1 & 3,3 & 0,3 & 0,0 & $-0,3$ \\
\hline 350 & 20,5 & 21,7 & 1,2 & 55,1 & 50,8 & 4,3 & 0,0 & 0,8 & 0,8 \\
\hline 400 & 20,5 & 21,4 & 0,9 & 55,0 & 51,1 & 3,9 & 0,0 & 1,0 & 1,0 \\
\hline 450 & 20,4 & 23,0 & 2,6 & 55,4 & 51,1 & 4,3 & 0,0 & 0,5 & 0,5 \\
\hline 500 & 20,0 & 21,4 & 1,4 & 55,2 & 49,0 & 6,2 & 0,5 & 1,0 & 0,5 \\
\hline 550 & 20,1 & 22,2 & 2,1 & 55,8 & 49,3 & 6,5 & 0,5 & 0,0 & $-0,5$ \\
\hline 600 & 19,7 & 20,9 & 1,2 & 55,6 & 49,4 & 6,2 & 0,4 & 1,4 & 1,0 \\
\hline 650 & 19,7 & 20,5 & 0,8 & 55,8 & 50,8 & 5,0 & 0,9 & 0,0 & $-0,9$ \\
\hline 700 & 19,5 & 20,8 & 1,3 & 55,3 & 50,7 & 4,6 & 0,4 & 0,5 & 0,1 \\
\hline 750 & 19,7 & 21,7 & 2,0 & 55,0 & 53,1 & 1,9 & 0,7 & 0,0 & $-0,7$ \\
\hline 800 & 19,9 & 21,6 & 1,7 & 55,6 & 50,9 & 4,7 & 0,0 & 0,0 & 0,0 \\
\hline 850 & 19,9 & 20,7 & 0,8 & 55,7 & 50,0 & 5,7 & 0,3 & 0,5 & 0,2 \\
\hline 900 & 19,8 & 20,6 & 0,8 & 55,1 & 49,9 & 5,2 & 0,0 & 0,6 & 0,6 \\
\hline 950 & 19,8 & 22,2 & 2,4 & 54,8 & 50,8 & 4,0 & 1,3 & 1,0 & $-0,3$ \\
\hline 1000 & 19,5 & 22,2 & 2,7 & 55,7 & 46,0 & 9,7 & 0,4 & 0,7 & 0,3 \\
\hline Média & $20,1 \mathbf{a}$ & $21,5 \mathbf{b}$ & 1,4 & $55,1 \mathbf{a}$ & $50,1 \mathbf{b}$ & 5,0 & $0,3 \mathbf{a}$ & $0,6 \mathbf{b}$ & 0,3 \\
\hline
\end{tabular}


manteve-se constante e foi em média $5 \%$ maior do que na área externa.

A maior diferença de temperatura entre os locais atingiu $2,7^{\circ} \mathrm{C}$. Sendo que a temperatura máxima no interior da área verde foi $20,8^{\circ} \mathrm{C}$ e no transecto móvel $23,0^{\circ} \mathrm{C}$. Com relação a umidade relativa, a maior diferença encontrada foi $9,7 \%$. No interior da área verde os valores nunca foram menores que $54,1 \%$, já e no transecto móvel o menor valor registrado foi $46,0 \%$.

Em pesquisas semelhantes realizadasem parquese bosquesde Curitiba, Silva et

al. (2013) verificaram que no interior do Bosque Gutierrez, que possui uma área de $18.000 \mathrm{~m}^{2}$, as temperaturas foram, em média, $4,4^{\circ} \mathrm{C}$ menores e a umidade relativa 17,8\% maior. Leal et al. (2011) verificaram que no interior do Bosque Estadual João Paulo II, que possui uma área de $48.000 \mathrm{~m}^{2}$, as temperaturas foram, em média, $0,9^{\circ} \mathrm{C}$ menores do que no percurso realizado, a umidade relativa $16 \%$ maior e a velocidade do vento $0,7 \mathrm{~m} / \mathrm{s}$ menor.

Biondi et al. (2011), no Bosque Capão da Imbuia, com área de $34.000 \mathrm{~m}^{2}$, verificaram que as temperaturas no interior do fragmento foram em média $3,6^{\circ} \mathrm{C}$ menores e a umidade relativa $14 \%$ maior.

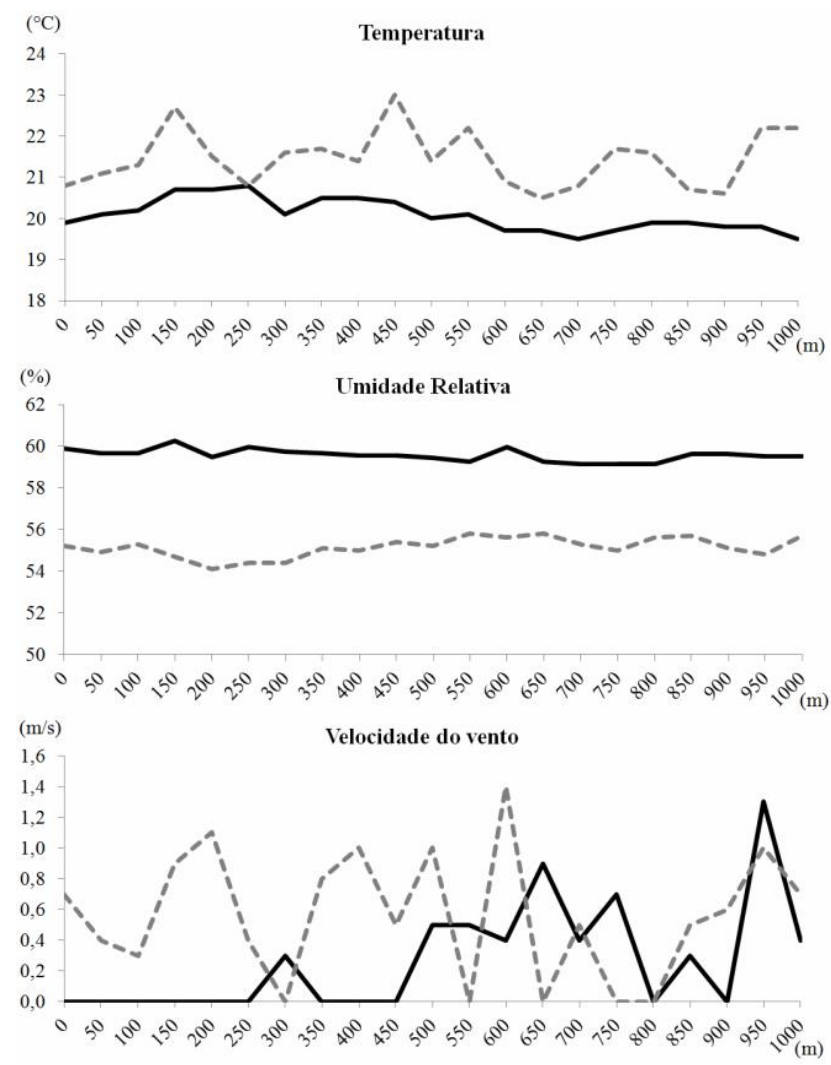

Interior do fragmento $-(-$ Transecto móvel

Figura 2 - Comportamento das variáveis meteorológicas no interior da área verde e no transecto móvel percorrido
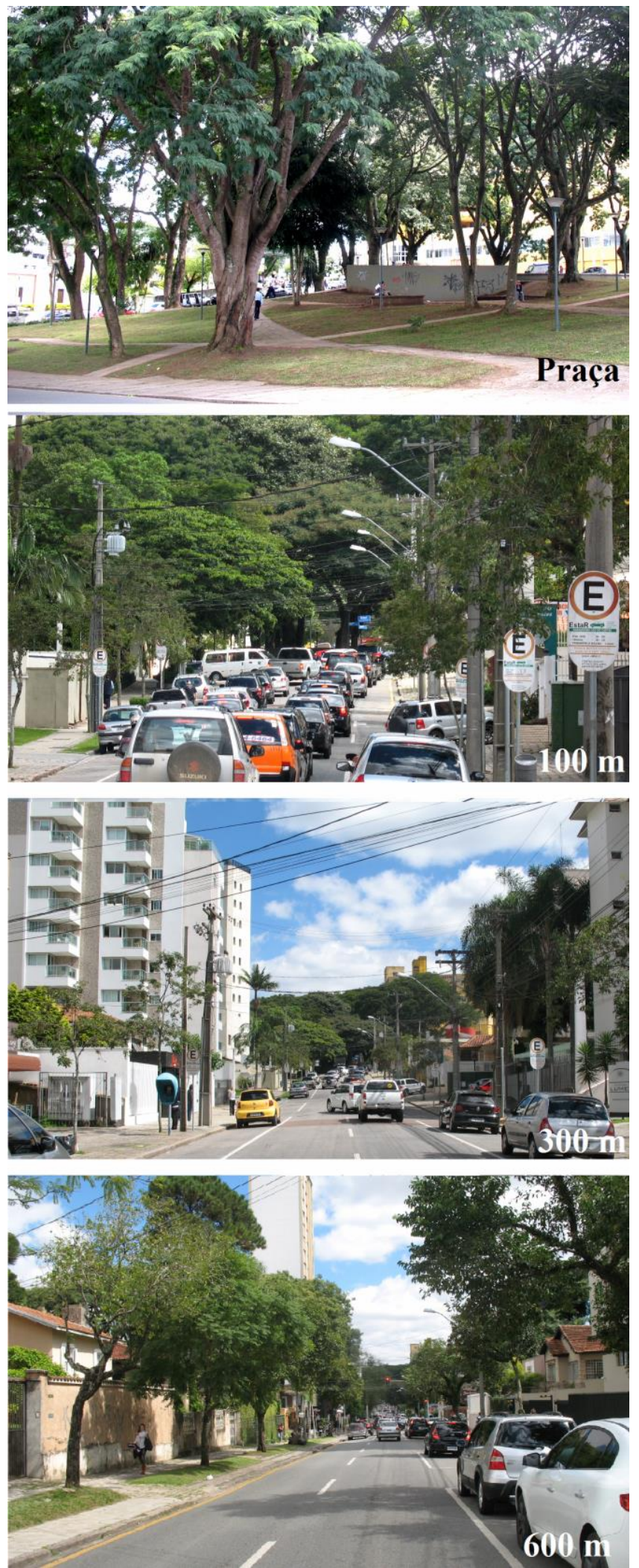

Figura 3 - Locais de coleta dos dados meteorológicos, no interior do fragmento e ao longo do transecto móvel percorrido 
Nos estudos descritos foram encontrados resultados mais significativos, uma vez que se trata de áreas com fragmentos florestais densos. No entanto, na presente pesquisa, foi possível constatar que mesmo uma área significativamente menor, e com vegetação introduzida, sem a presença de remanescentes florestais, também pode proporcionar uma influência relevante no microclima urbano.

No interior da área verde foi possível observar que as variáveis meteorológicas apresentaram um comportamento mais estável do que no percurso realizado (Figura 2). Estas alterações devem-se à composição da estrutura urbana (Figura 3).

Podem-se observar no gráfico da temperatura as oscilações ocorridas no transecto móvel. Na distância de $250 \mathrm{~m}$, os valores registrados nos dois locais foram iguais, isto porque no transecto móvel o ponto de coleta das variáveis meteorológicas foi embaixo de uma árvore de copa densa, similar a condição existente na praça.

A umidade relativa, embora diretamente influenciada pela temperatura, apresentou tendência com pouca oscilação.

Para a velocidade do vento não foi possível determinar a influência do fragmento florestal. Segundo Ochoa de La Torre (1999), nos ambientes urbanos, com alta densidade de construções, os ventos, próximos ao solo, são influenciados principalmente pelos seguintes aspectos da estrutura urbana: largura das ruas, altura dos edifícios, continuidade e direção do emaranhado urbano, diferenças entre as alturas de construção e outros, fazendo com que a vegetação apresente um efeito menos significativo.

A existência de arborização na Al. Augusto Stellfeld dificultou a interpretação dos resultados, uma vez que alguns pontos foram coletados embaixo de árvores. Desta forma, alguns pontos do transecto apresentaram condições microclimáticas semelhantes às verificadas na praça. Por este motivo, o raio de influência desta praça no seu entorno não pode ser determinado, sendo observado a apenas a aproximadamente $200 \mathrm{~m}$.

Este fato, porém, mostra a influência microclimática das áreas verdes que, quando vegetadas com espécies de grande porte e somadas à arborização de ruas, podem resultar em grandes benefícios ecológicos à população.

\section{Conclusões}

O levantamento meteorológico expedito realizado nesta pesquisa permitiu verificar que o microclima na praça caracteriza-se por valores menores de temperatura e maiores de umidade relativa, quando comparados à via de seu entorno.

Devido a arborização composta por indivíduos de grande porte, a Praça Alfredo Andersen contribui para a melhoria climática da cidade, principalmente nas áreas mais próximas.

\section{Agradecimentos}

À Fundação Araucária de Apoio ao Desenvolvimento Científico e Tecnológico do Paraná pelo financiamento à compra dos equipamentos.

\section{Referências}

AMORIM, M. C. C. T. Climatologia e gestão do espaço urbano. Mercator, Fortaleza, número especial, p. 71-90, 2010.

BIONDI, D. ; BATISTA, A. C. ; MARTINI, A. ; GRISE, M. M. O efeito microclimático do bosque Capão da Imbuia na cidade de Curitiba-PR, Brasil. In: CONGRESO FORESTAL LATINOAMERICANO, 5., 2011, Lima. Anais... Lima: [s.n.], 2011. Não paginado.

BIONDI, D.; LIMA NETO, E. M. Distribuição espacial e toponímia das praças de Curitiba - PR. REVSBAU, Piracicaba - SP, v.7, n.3, p.31-43, 2012.

BRITO, D. R. S.; RAABE, J.; SOUSA, W. C.; MELO, R. R.; PEDROSA, T. D. Diagnóstico da arborização das praças públicas no municípios de Bom Jesus, Piauí. Scientia Plena, v.8, n.4, 2012.

GARTLAND, L. Ilhas de calor: como mitigar zonas de calor em áreas urbanas. São Paulo: Oficina de Textos, 2010. 223 p.

HAMADA, S.; OHTA, T. Seasonal variations in the cooling effect of urban green areas on surrounding urban areas. Urban Forestry \& Urban Greening, Davis, v.9, p. 15-24, 2010.

LEAL, L.; MARTINI, A.; BIONDI, D.; BATISTA, A. C. Levantamento meteorológico expedito para análise da influência microclimática do Bosque Estadual João Paulo II, Curitiba - PR. In: ENCONTRO SUL-BRASILEIRO DE METEOROLOGIA, 4., 2011, Pelotas/RS. Anais... Pelotas: SBMET, 2011. p. 1-9.

LOMBARDO, M. A.; SILVA FILHO, D. F; FRUEHAUF, A. L.; PAVAN, D. C. O uso de geotecnologias na análise de da ilha de calor, índice de vegetação e uso da terra. Revista Geonorte, Edição Especial 2, v.2, n.5,p.520-529 ,2012.

MATOS, E.C.A; NASCIMENTO-JÚNIOR, J.E; MARIANO, D.L.S; OLIVEIRA, A.L. Arborização do bairro centro da cidade de Aracaju, Sergipe, e seus organismos associados. REVSBAU, Piracicaba - SP, v.5, n.4, p.22-39, 2010.

MILANO, M.S. O planejamento da arborização, as necessidades de manejo e tratamentos culturais das 
árvores de ruas de Curitiba, PR. Revista Floresta, Curitiba, v.17, n.12, p.15-21, 1987.

OCHOA DE LA TORRE, J. M. La vegetación como instrumento para el control microclimático en línea. Não paginado. Tesis (Doctor en Arquitectura) - Escola Tècnica Superior d'Arquitectura de Barcelona, Universidad Politécnica de Cataluña, 1999.

SHASHUA-BAR, L.; PEARLMUTTER, D.; ERELL, E. The cooling efficiency of urban landscape strategies in a hot dry climate. Landscape and Urban Planning, Amsterdam, v.92, p.179-186, 2009.

SILVA, D. A.; BIONDI, D.; MARTINI, A.; VIEZZER, J. Influência Microclimática do Bosque Gutierrez na Cidade de Curitiba-PR, Brasil. In: Simpósio internacional de climatologia, 2013, Florianópolis. Anais... Florianópolis, 2013.

SUCOMINE, N.M.; GIACOMELLI, D.C.; SHAMS, J.A.; SILVA FILHO, D.F.; LIMA, A.M.L.P., SALES, A. Análise microclimática de uma área verde e de seu entorno imediato. Anais... In: SIMPGEU - Simpósio de PósGraduação em Engenharia Urbana. Maringá, 2009. p.1-10.

VIERO, V. C.; BARBOSA FILHO, L. C. Praças públicas: origem, conceitos e funções. In: JORNADA DE PESQUISA E EXTENSÃO. Anais... ULBRA. Santa Maria, p.1-3, 2009.

YU, C.; HIEN, W. N. Thermal benefits of city parks. Energy and Buildings, Lausanne, v.38, p.105-120, 2006. 